\title{
How to Get Your Students to Stop Translating and Start Thinking in English
}

\author{
Erick Kemal \\ Madrasah Tsanawiyah Negeri 3 Malang \\ MTsN 3 Malang \\ Malang, Indonesia \\ erickcianjur@gmail.com
}

\begin{abstract}
This research is aimed to describe how to get your students to stop translating and start thinking in English. Students usually translate things in their heads before presenting their ideas. We seldom have students who provide a natural sounding reply, spontaneously and automatically, without even blinking an eye. Our goal as teachers is to guide students towards increasingly thinking in English and drop the crutch of translation. But we all know this is precisely one of the hardest things to achieve. Why it's so important for ESL students to stop translating and start thinking in English: 1. Consider their main goal. They want to learn to speak English, not become translators. 2. It's counter-productive. The constant comparison of one language to another hinders naturally flowing speech. Experienced interpreters are real pros at this, but your students are not. 3. Some things are simply too hard to translate. This creates a situation where the student is desperately trying to remember how to say the one word they have in their minds in English, while they should be trying to recall a recent lesson instead. When you remove translation from your language learning process, you can learn to think in your target language from the beginning.
\end{abstract}

\section{Keywords-language; ESL student}

\section{INTRODUCTION}

This is every ESL students dream, and one of the most important steps in learning a new language. To think in that language means you have really 'got it'. But how can you start training your brain to do this? Let's first look at some scientific facts. Research has shown that in fact no one 'thinks in a language', they 'think in ideas', and ideas are the same everywhere. So that means all of us are starting from the same place, no matter where in the world we come from, inside our heads, it's all the same.

Thinking in English while learning it is definitely a challenge for students, especially the ones immersed in an EFL environment. Since learners practice the language mainly in class, the process of acquiring English demands more time, effort and persistence. Nevertheless, this goal can certainly be achieved; we have all experienced it ourselves, regardless of having been in an ESL or EFL context. So, what about our students? Can we explain to them how to think in English? Beginners who experience more difficulty when having to think in another language since they lack a good command of grammatical structures, pronunciation, and their vocabulary are usually limited. However, this does not imply that students in other proficiency levels do not experience this challenge; it might occur but to a lesser extent. Given that students at the beginning levels struggle more with having thoughts in English, they need to be encouraged to monitor their speech, realize when they use the wrong structures, be able to correct them and avoid making the same mistakes again. Obviously, they must be aware of how necessary it is to think in the second or foreign language and how this helps them improve their level.

\section{LITERATURE REVIEW}

\section{A. Teaching English as a Foreign Language to Young Learners}

The way children learn a foreign language, and therefore the way to teach it, obviously depends on their developmental stage. The question of weather or not to use the mother tongue in the English classroom is an open one. It is essential to use English as possible in class. What important is the children are given clear guidelines on when they are expecteg to use English and when their first language is permissible.

Children can be bilingual in two ways: (1) by acquiring both languages at the same time in early childhood, or (2) by learning a second language after mastering the first. Children of bilingual parents who teach both languages in the early years show no special problems with language development. For a time, they appear to develop more slowly because the mix the two languages. But this is not indication of linguistic confussion, since bilingual parents do not maintain strict language saparation either. Instead, it reflects the young child's desire to use any means available to mommunicate as cited in [1].

In fact, the goal of schooling could reasonably be boardened to include helping all children become bilingual, thereby fostering the cognitive, language, and cultural enrichment of the entire nation.

\section{B. Classroom Language}

An area where English should be use as much as possible is the everyday organization and running of the classroom. Both the teacher and children can use English here; in fact, 
this classroom language is one of the most realistic communication situation in which the children find themselves. It is not difficult to give instructions for the usual classroom routines in English.

\section{How to Think in another Language without Translating}

When you start learning a foreign language, everything appears completely new to you, except the words that you might recognise from your own language or other languages you have learned. Your brain has to get used to a completely new set of sounds, a new vocabulary, and new ways of putting sentences together. You have to try hard to pick out words from the stream of information that you don't understand.

The process of learning to speak a foreign language is similar. At the beginning, you might learn some simple phrases which you will have to pull out of your brain when you want to talk, or you might have practised certain types of sentences or grammar patterns, which you have to think about and form slowly. In comparison with your native tongue, the foreign language seems very unnatural, and it is not the thing you "think of first." Students will often ask, "How do you say ... in English?" which shows how much they are falling back on their native language, "to make things make sense" or "as a place to start from."

How often do you have students who translate things in their heads before answering you? By contrast, how often do you have students who provide a natural-sounding reply, spontaneous-ly and automatically, without even blinking an eye? Chances are most of your students still translate in their heads at least some of the time. Our goal as teachers is to guide students towards increasingly thinking in English and drop the crutch of translation. But we all know this is precisely one of the hardest things to achieve. So how do we do that? How can we effectively get our ESL students to think in English?

Why it's so important for ESL students to stop translating and start thinking in English:

- Consider their main goal. They want to learn to speak English, not become translators. There's no point in them speaking their native language in their heads while they're trying to learn another.

- It's counterproductive. The constant comparison of one language to another hinders naturally flowing speech. Experienced interpreters are real pros at this, but your students are not.

- $\quad$ Some things are simply too hard to translate. This creates a situation where the student is desperately trying to remember how to say the one word they have in their minds in English, while they should be trying to recall a recent lesson instead.

Now, that we've established the importance of getting students to think in English for the duration of the class, let's see ways to help them achieve this ever elusive state.

How to get your Students to Stop Translating and Start Thinking in English.
1) Use actions as much as possible to build the connection between the idea and the English word.

When we are a child and we are learning to speak, this is exactly what we do, we make connections between actions, ideas and thoughts to words. The ESL learner does this too, only a lot faster. When you teach feelings like "sad", "happy", "scared", etc. It's a lot simpler to translate them. But it's so much more fun to act them out for you and your class! The same goes for actions like opening closing things, walking, running, etc. The more you can make these connections the easier it will be for your brain to make the link to English.

When we are a child and we are learning to speak, this is exactly what we do, we make connections between actions, ideas and thoughts to words. The ESL learner does this too, only a lot faster. When you teach feelings like "sad", "happy", "scared", etc. It's a lot simpler to translate them. But it's so much more fun to act them out for you and your class! The same goes for actions like opening closing things, walking, running, etc. The more you can make these connections the easier it will be for your brain to make the link to English.

\section{2) Don't use a bilingual dictionary.}

If you teach ESL by only speaking English in class, then you often supply definitions or explanations of words in English. Ask students to use Eng-Eng dictionaries, and it will contribute for your efforts.

\section{3) Use Visual Aids.}

Like miming, visual aids such as flashcards, illustrations, posters and even video are great ways to avoid translation. In this way you will see the image and also the words. This makes the link very easy.

4) Use opposites or synonyms.

Use words, they already know leading in questions: Are you happy to see your friend? You're glad to see him. Check out these other great ways to teach vocabulary. No translation needed at all!

\section{5) Teach language in groups.}

The need for translation will be eliminated if you teach words in groups that make sense, for example, "eat" and "drink" with a list of food items. 
6) Learn chunking answers.

This is simple, when someone says "How are you?", you already know the answer "Fine thanks." Why do you know this answer?, Why do you never have to translate this sentence into your language and then translate your answer back? Because you have learned it with the question. Remembering a group of words together is called called 'chunking'. The same goes for lists. Remember all of the list together, e.g. food words, education words, action words, etc. e.g. go swimming, listen to music, eat fish.

\section{7) Introduce as set phrases.}

Has a student ever asked you to translate the meaning of "You're welcome"? In most languages a literal translation is ridiculous, but providing a similar phrase in the students' native language is not necessary, either. When students ask for translation simply say a set phrase is a set phrase. Make sure they understand it's a reply to "Thank you". They will probably figure out the equivalent in their language, but with some expressions an equivalent is hard to come by - think of proverbs or idiomatic expressions. The goal is for them to understand the meaning of the phrase and when it's used.

8) Practice English for school.

English for School is used to fulfill students' need to learn English for Specific Purposes. It can involve daily expression, students' classroom language, teacher's classroom language and educational terms.
Possible problems in get your students to stop translating and start thinking in English are: (1) Longer time is spent on clarifying language, (2) Students'expectations and fear. It is completely possible to learn a language "naturally, without translation," but that might not be the quickest way in. it is a process that you will benefit from much more later, but don't let that worry you; the process of naturalising yourself is an amazing journey. It might even open up your mind or change your life. It will take time, but it cuts that journey of speaking process.

Thinking in English really just means getting out of your local language social circle and pushing yourself. It won't happen overnight, but it will happen. When you remove translation from your language learning process, you can learn to think in your target language from the beginning.

\section{CONCLUSION}

It is completely possible to learn a language "naturally, without translation," but that might not be the quickest way in. it is a process that you will benefit from much more later, but don't let that worry you; the process of naturalising yourself is an amazing journey. It might even open up your mind or change your life. It will take time, but it cuts that journey of speaking process.

Thinking in English really just means getting out of your local language social circle and pushing yourself. It won't happen overnight, but it will happen. When you remove translation from your language learning process, you can learn to think in your target language from the beginning.

\section{References}

[1] Berk, Laura E. Child Development. Four Edition. Illinois State University. USA 